\title{
Primary glioblastoma in the pineal region: a case report and review of the literature Kyung-Sub Moon ${ }^{1}$, Shin Jung*1, Tae-Young Jung1, In-Young Kim¹, Min- Cheol Lee ${ }^{2}$ and Kyung-Hwa Lee 3
}

Address: ${ }^{1}$ Department of Neurosurgery, Chonnam National University Research Institute of Medical Sciences, Chonnam National University Hwasun Hospital \& Medical School, Gwangju, Republic of Korea, ${ }^{2}$ Department of Pathology, Chonnam National University Medical School, Gwangju, Republic of Korea and ${ }^{3}$ Department of Pathology, Seonam University, College of Medicine, Namwon, Republic of Korea

Email: Kyung-Sub Moon - moonks@chonnam.ac.kr; Shin Jung* - sjung@chonnam.ac.kr; Tae-Young Jung - tongbori@hanmail.net; InYoung Kim - kiy87@hanmail.net; Min-Cheol Lee - mclee@chonnam.ac.kr; Kyung-Hwa Lee - azimmed@hanmail.net

* Corresponding author

Published: 27 August 2008

Journal of Medical Case Reports 2008, 2:288

Received: 15 January 2008

Accepted: 27 August 2008

This article is available from: http://www.jmedicalcasereports.com/content/2/1/288

(c) 2008 Moon et al; licensee BioMed Central Ltd.

This is an Open Access article distributed under the terms of the Creative Commons Attribution License (http://creativecommons.org/licenses/by/2.0), which permits unrestricted use, distribution, and reproduction in any medium, provided the original work is properly cited.

\begin{abstract}
Introduction: Glioblastoma in the pineal region is extremely rare with only a few cases reported in the literature.

Case presentation: A 68-year-old man presented with a sudden deterioration manifesting as a headache, vomiting and gait disturbance. A magnetic resonance imaging study revealed a heterogeneously ring-enhanced mass in the pineal region. The mass was subtotally removed through the occipital transtentorial approach, and diagnosed as a glioblastoma.

Conclusion: We discuss the clinical course, radiological findings and treatment strategies of pineal glioblastoma with a review of the relevant literature.
\end{abstract}

\section{Introduction}

The pineal region consists of the pineal body, the posterior wall of the third ventricle, tela choroidea and velum interpositum. Despite its small size, a wide variety of brain tumors can arise in the pineal region. Tumors of the pineal body may be of pineal parenchymal origin, of extragonadal germ cell origin, or of neuroglial origin [1]. Approximately $11-28 \%$ and $50-75 \%$ of tumors in the pineal region are pineal parenchymal tumors and germ cell tumors, respectively [1]. In addition, glioma, meningioma and mesenchymal tumors are encountered occasionally. Glioblastoma, which is the most malignant and frequent glioma in brain tumors, is extremely rare in the pineal region with only 17 cases being reported in the literature [2-13]. This paper presents a case of glioblastoma arising in the pineal region and discusses its clinical course, radiological findings and treatment strategies with a review of the relevant literature.

\section{Case presentation}

A 68-year-old man presented with a sudden deterioration manifesting as a headache, vomiting and gait disturbance. Two months earlier, he had begun to notice intermittent headaches. Neurological testing revealed ataxic gait features and bilateral papilledema without other neurological deficits. The computed tomography (CT) scan revealed obstructive hydrocephalus caused by a round hypodense ill-defined lesion in the pineal region (Fig. 1A). A magnetic resonance (MR) imaging study demonstrated a $4 \times 3$ $\times 4 \mathrm{~cm}$ mass at the pineal gland. Through the administration of gadolinium, the lesion showed a heterogeneous hypointensity on the $\mathrm{T}_{1}$-weighted image and hyperinten- 


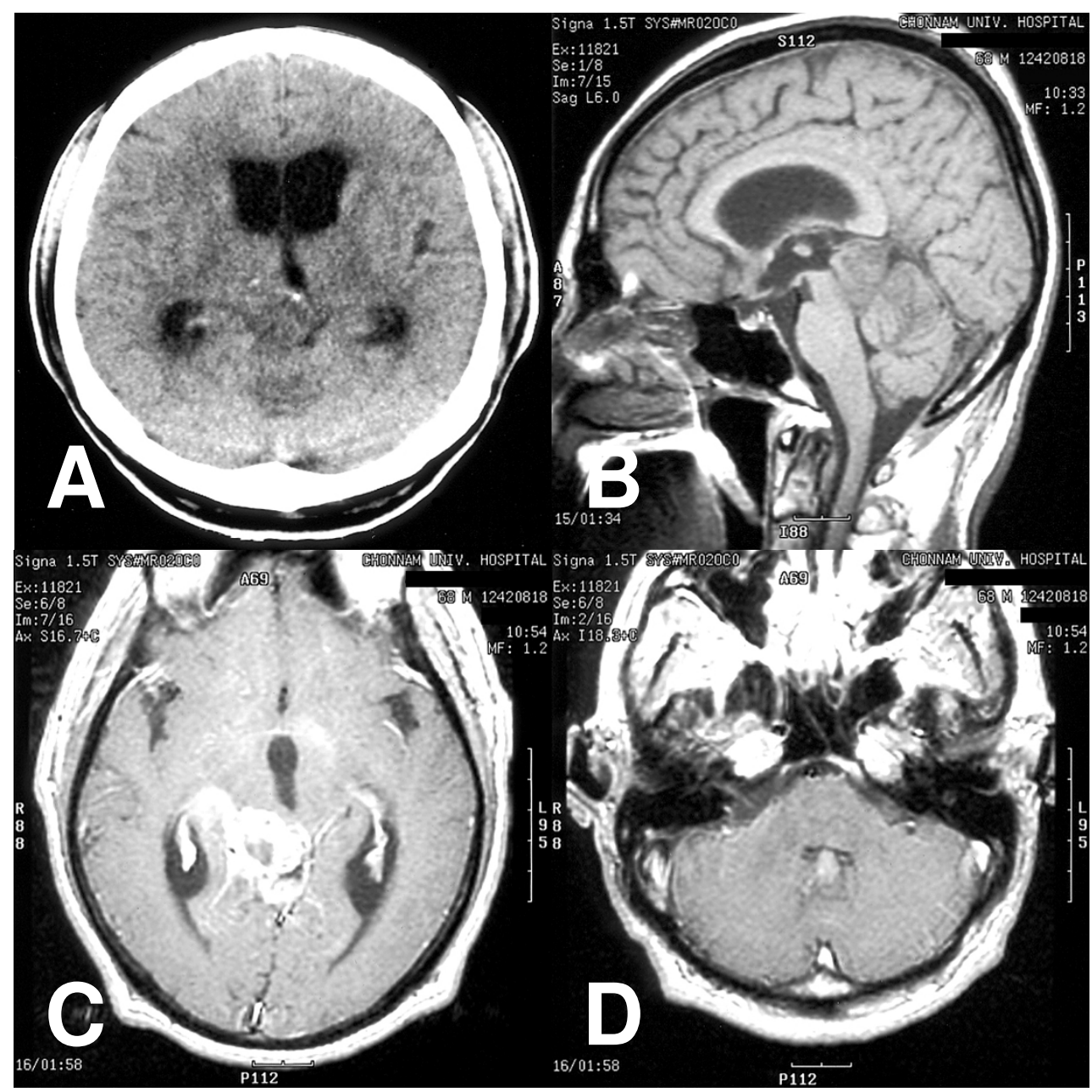

Figure I

Non-contrast computed tomography scan showing a hypointense mass in the pineal region (A). $T_{1}$-weighted sagittal (B) and gadolinium-diethylenetriaminepentaacetic acid enhanced axial (C and D) magnetic resonance images demonstrating a heterogeneously ring-enhanced mass with central necrosis in the pineal region and ependymal dissemination in the fourth ventricle.

sity on the $\mathrm{T}_{2}$ image as well as ring-enhancement with an extension into the midbrain and thalamus (Fig. 1B and 1C). No hematological or biochemical abnormalities were evident, and the other tumor markers, such as $\alpha$-fetoprotein, $\beta$-human chorionic gonadotrophin and placental alkaline phosphatase were within normal limits. Surgery was performed using the occipital transtentorial approach because a non-germinomatous malignant tumor was considered a possibility. During the operation, a very soft, gray-colored mass was located in the pineal region, which was barely demarcated from the peritumoral brain. Some hard portions were found in the tumor. An examination of frozen biopsy samples showed anaplastic astrocytic tumor cells. The mass was subtotally removed due to adhesion with the hypothalamus and midbrain, and its severe bleeding nature. The pathologic findings revealed a typical glioblastoma consisting of frequent mitotic figures, a high proliferation index, microvascular proliferation with endothelial cell hyperplasia, and extensive necrosis with focal pseudopalisading (Fig. 2A). Immunohistochemistry revealed a positive reaction to the glial fibrillary acidic protein in both cell bodies and processes (Fig. 2B). A further review of the pre-operative MR imaging study showed an enhanced mass in the fourth ventricle that was consistent with ependymal dissemination (Fig. 1D). Two weeks after surgery, the patient underwent a ventriculoperitoneal shunt due to the rapid exacerbation of signs and symptoms of the hydrocephalus. Considering the pathological and radiological findings, whole neuraxis irradiation therapy was recommended. However, his 


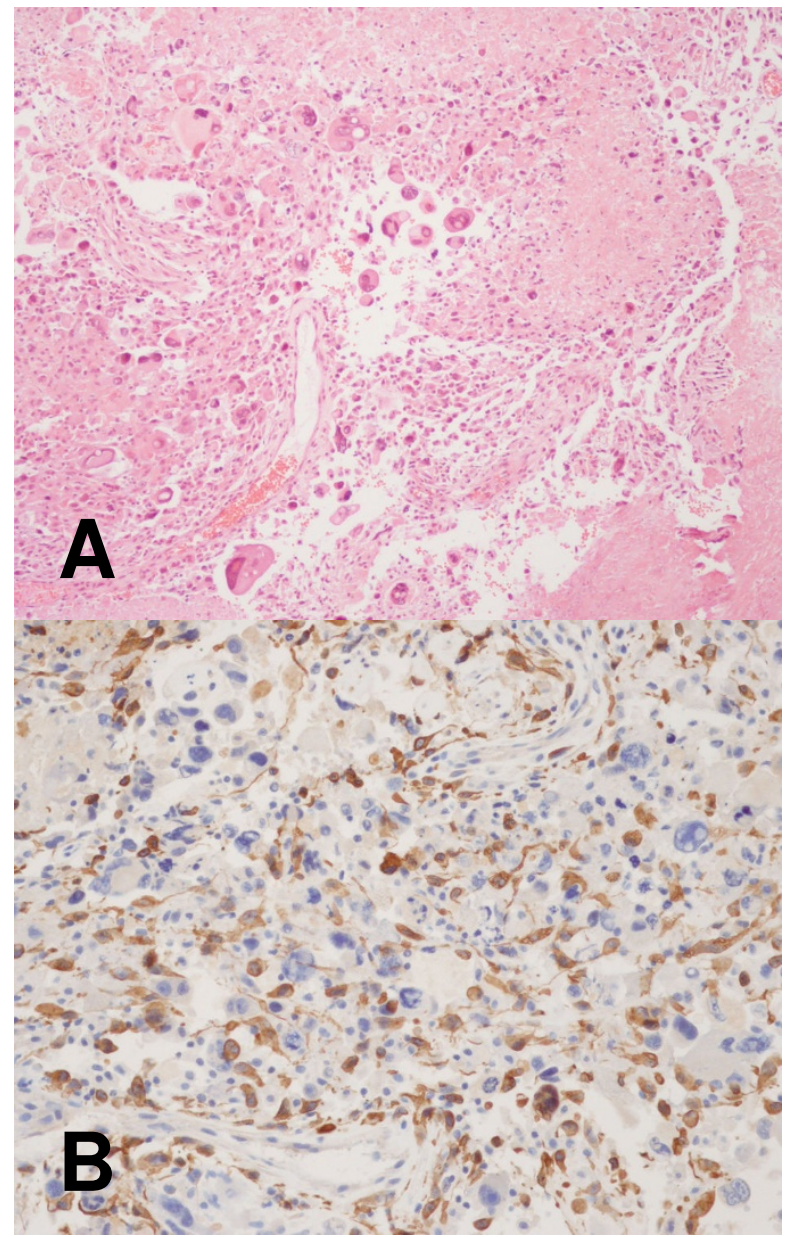

\section{Figure 2}

(A) Photomicrograph showing numerous anaplastic astrocytic tumor cells with mitosis, large multinucleated giant cells with abundant eosinophilic cytoplasm, and an extensive area of necrosis. (B) Photomicrograph of the immunohistochemical study showing a positive reaction for the glial fibrillary acidic protein (GFAP) (A: hematoxylin and eosin stain, original magnification, $\times 100$, B: original magnification, $\times 200)$.

family insisted on conservative medical support. The patient died 2 months after the diagnosis.

\section{Discussion}

Pineal gliomas include fibrillary astrocytoma, pilocytic astrocytoma, anaplastic astrocytoma, glioblastoma, oligodendroglioma, ependymoma and choroid plexus papilloma [1]. Among these entities, well differentiated astrocytomas are the most common [1]. Since the report of Bradfield and Perez in 1972 [3], only 18 cases including this one have described a glioblastoma of the pineal region (Table 1) [2,4-13]. The patients reported with a pineal glioblastoma consisted of nine women and six men aged from 5 to 68 years (mean, 39.3 years). Compared with those of germ cell or parenchymal tumors in the pineal gland, pineal glioblastomas occur in middle aged adults with a slight female preponderance.

All reported cases of pineal glioblastomas have presented with signs or symptoms of increased intracranial pressure and hydrocephalus. Eight patients $(57.1 \%)$ with a pineal glioblastoma also presented with visual or gaze disturbances, including diplopia, blurry vision, nystagmus and upgaze palsy, which were mainly consistent with Parinaud's syndrome. However, the clinical symptoms and signs of pineal glioblastomas are similar to other tumors in the pineal region, which makes them difficult to diagnose based on the clinical history and presentation alone.

MR imaging of pineal glioblastomas demonstrate characteristic features. Heterogeneous enhancement with a centrally located non-enhanced portion indicates central necrosis. Infiltration into the surrounding structures, such as midbrain and thalamus, is shown as hyperintensity on the $\mathrm{T}_{2}$-weighted $\mathrm{MR}$ image, extending beyond the margin of the enhanced mass. Despite its rapid and infiltrative nature, glioblastomas generally do not invade the subarachnoid space, and rarely metastasize through the cerebrospinal fluid pathway [14]. However, a review of pineal glioblastoma revealed leptomeningeal or ventricular dissemination to be quite common (7 in 10 available cases). Among these cases, two cases, including the present one, showed pre-operative dissemination on the initial radiological study. Upon a careful review of pre-operative MR imaging for a pineal region mass, an enhancing nodule in the subarachnoid space or ventricle system can assist in the diagnosis of glioblastoma.

Considering that most patients with pineal glioblastoma multiforme (GBM) show symptoms and signs of hydrocephalus, an endoscopic third ventriculostomy and tissue biopsy may be an appropriate treatment for pineal glioblastoma. However, according to Amini et al. [2], this procedure was unable to resolve the hydrocephalus over time and obtain sufficient tissue samples in two out of three cases. The benefit of an aggressive surgical resection in the treatment of pineal GBM is unclear. Two patients who underwent a surgical resection only, including ours, died 2 months after the diagnosis [8]. The average survival in the three cases who received radiation therapy alone was 3.3 months (range, 2 to 4 months) $[2,7,10]$. However, adjuvant radiation therapy and/or chemotherapy after a surgical resection may prolong the survival of patients with a pineal glioblastoma. The three patients who underwent a surgical resection and radiation therapy lived an average of 5.3 months (range, 4 to 6 months) $[4,9,13]$. Furthermore, the mean survival duration of the four 
Table I: Summary of reported cases of pineal glioblastoma multiforme

\begin{tabular}{|c|c|c|c|c|c|c|}
\hline Author/Year & Age/Sex & Symptoms & Radiological findings & $\begin{array}{l}\text { Leptomeningeal } \\
\text { dissemination }\end{array}$ & Treatment & Survival \\
\hline Bradfield et al.// 972 & $53 / F$ & $\mathrm{~N}-\mathrm{A}$ & $\begin{array}{l}\text { Obstructive HDC, mass in } \\
\text { post. 3rd ventricle }\end{array}$ & No on autopsy & Resection & Postoperative death \\
\hline Bradfield et al.// 972 & $5 / F$ & $\mathrm{~N}-\mathrm{A}$ & $\begin{array}{l}\text { Obstructive HDC, mass in } \\
\text { post. 3rd ventricle }\end{array}$ & No on autopsy & Shunt & 27 mos \\
\hline DeGirolami et al.// 973 & 3 cases & $\begin{array}{l}\text { Intracranial hypertension, } \\
\text { vertical gaze palsy in one } \\
\text { case }\end{array}$ & $\mathrm{N}-\mathrm{A}$ & $\mathrm{N}-\mathrm{A}$ & $\begin{array}{l}\text { RT for all cases, Resection } \\
\text { for only one case }\end{array}$ & $\mathrm{N}-\mathrm{A}$ \\
\hline Kalyanaraman/I 979 & $68 / F$ & $\begin{array}{l}\text { Ataxia, confusion, urinary } \\
\text { incontinence, upgaze } \\
\text { limitation }\end{array}$ & $\begin{array}{c}\mathrm{CT}: \mathrm{HDC}, \text { calcified midline } \\
\text { mass }\end{array}$ & $\mathrm{N}-\mathrm{A}$ & Resection, RT & $4 \mathrm{mos}$ \\
\hline Norbut et al.//98I & $36 / M$ & $\begin{array}{l}\text { HA, blurry vision, Parinaud's } \\
\text { syndrome }\end{array}$ & $\begin{array}{l}C T: H D C \text {, mass in post. } 3 r d \\
\text { ventricle }\end{array}$ & $\begin{array}{l}\text { Yes on autopsy (4th } \\
\text { ventricle, leptomeninges of } \\
\text { cerebral cortex, } \\
\text { interpeduncular fossa, brain } \\
\text { stem, and spinal cord) }\end{array}$ & Shunt, RT & 4 mos \\
\hline Frank et al.// 985 & $52 / F$ & $\begin{array}{l}\text { Intracranial hypertension, } \\
\text { oculomotor disturbances }\end{array}$ & HDC, mass in $3 r d$ ventricle & $\mathrm{N}-\mathrm{A}$ & Stereotactic biopsy, RT & 4 mos \\
\hline Edwards et al.// 988 & $12 / F$ & $\mathrm{~N}-\mathrm{A}$ & $\mathrm{N}-\mathrm{A}$ & $\mathrm{N}-\mathrm{A}$ & $\begin{array}{l}\text { Resection, RT, } \\
\text { Chemotherapy }\end{array}$ & $18 \mathrm{mos}$ \\
\hline Vaquero et al.// 990 & 63/M & HA, changing of behavior & $\begin{array}{l}C T \text { : rounded hyperdense } \\
\text { mass with ring enhancement }\end{array}$ & $\mathrm{N}-\mathrm{A}$ & $\begin{array}{l}\text { Shunt, Resection, Whole } \\
\text { brain RT }\end{array}$ & $6 \mathrm{mos}$ \\
\hline Pople et al.//993 & $6 / F$ & $\begin{array}{l}\text { HA, N/V, diplopia, decreased } \\
\text { visual acuity, 6th cranial } \\
\text { nerve palsy, upgaze limitation }\end{array}$ & $\begin{array}{l}\text { CT \& MR: } \\
\text { mass }\end{array}$ & $\begin{array}{c}\text { Yes on FU CT (frontal \& } \\
\text { occipital lobes, scattered } \\
\text { leptomenges) }\end{array}$ & $\begin{array}{c}\text { Shunt, Resection, local RT, } \\
\text { Chemotherapy }\end{array}$ & 4 mos \\
\hline Cho et al.// 998 & $10-15 / F$ & $\mathrm{~N}-\mathrm{A}$ & $\mathrm{N}-\mathrm{A}$ & $\mathrm{N}-\mathrm{A}$ & Resection, RT & $6 \mathrm{mos}$ \\
\hline Gasparetto et al./2003 & 29/F & $\begin{array}{l}\text { HA, drowsiness, fever, } \\
\text { dizziness, seizure, }\end{array}$ & $\begin{array}{l}\text { CT \& MR: ill-defined } \\
\text { heterogeneously enhanced } \\
\text { mass with extension to } \\
\text { thalamus }\end{array}$ & No & Shunt, Resection & $2 \mathrm{mos}$ \\
\hline Toyooka et al./2005 & $49 / M$ & $\begin{array}{l}\text { HA, diplopia, memory } \\
\text { disturbance }\end{array}$ & $\begin{array}{c}\text { MR: irregular } \\
\text { heterogeneously enhanced } \\
\text { mass }\end{array}$ & $\begin{array}{l}\text { Yes on FU MR (lateral } \\
\text { ventricle, pons, } \\
\text { pontomedullary junction) }\end{array}$ & $\begin{array}{c}\text { Shunt, Resection, } \\
\text { Chemotheraphy (ACNU), } \\
\text { local RT }\end{array}$ & $11 \mathrm{mos}$ \\
\hline Amini et al./2006 & $40 / M$ & $\begin{array}{l}\mathrm{HA}, \mathrm{N} / \mathrm{V} \text {, diplopia, blurry } \\
\text { vision }\end{array}$ & $\begin{array}{c}\text { CT: Obstructive HDC, } \\
\text { strong enhancement, } \\
\text { punctuate calcification } \\
\text { MR: heterogenously } \\
\text { enhancing with central } \\
\text { necrosis, extension into } \\
\text { midbrain }\end{array}$ & $\begin{array}{c}\text { Yes on initial MR } \\
\text { (cbll, medulla, temporal lobe) }\end{array}$ & $\begin{array}{l}\text { Endoscopic TVB, Resection, } \\
\text { Shunt, Whole brain RT, } \\
\text { Chemotherapy (Temodar) }\end{array}$ & $5 \mathrm{mos}$ \\
\hline Amini et al./2006 & $43 / M$ & $\begin{array}{l}\text { HA, disequilibrium, } \\
\text { decreased level of mental } \\
\text { status }\end{array}$ & $\begin{array}{l}\text { MR: heterogenously } \\
\text { enhancing, HDC }\end{array}$ & $\begin{array}{l}\text { Yes on FU MR } \\
\text { (intraventricular) }\end{array}$ & $\begin{array}{l}\text { TVB, Resection, Whole } \\
\text { brain RT, Chemotherapy }\end{array}$ & $7 \mathrm{mos}$ \\
\hline Amini et al./2006 & $52 / F$ & $\begin{array}{l}\text { HA, N/V, diplopia, blurry } \\
\text { vision, upgaze palsy }\end{array}$ & $\begin{array}{c}\text { MR: heterogenously } \\
\text { enhancing with central } \\
\text { necrosis, obstructive HDC }\end{array}$ & $\begin{array}{c}\text { Yes on FU MR (lateral } \\
\text { ventricle, leptomeninges of } \\
\text { brain \& spine) }\end{array}$ & Endoscopic TVB, RT & $2 \mathrm{mos}$ \\
\hline Present case/2006 & $68 / M$ & $\mathrm{HA}, \mathrm{N} / \mathrm{V}$, Ataxia & $\begin{array}{c}\text { CT: HDC, hypodense mass } \\
\text { MR: irregular } \\
\text { heterogeneously ring- } \\
\text { enhanced mass with central } \\
\text { necrosis }\end{array}$ & $\begin{array}{c}\text { Yes on initial MR (4th } \\
\text { ventricle) }\end{array}$ & Resection, Shunt & $2 \mathrm{mos}$ \\
\hline
\end{tabular}

F, female; FU, follow-up; M, male; mos, months; MR, magnetic resonance; CT, computed tomography; HA, headache; N/V, nausea \& vomiting; HDC, hydrocephalus; RT, radiation therapy; N-A, not available; post., posterior; TVB, third ventriculostomy \& biosy 
patients who received radiation therapy and chemotherapy after the surgical resection was 7 months (range, 4 to 11 months) $[2,11,12]$.

The overall prognosis of a patient with a pineal glioblastoma is poor. Despite every effort in treatment, the maximum survival duration is less than 1 year after diagnosis (except for a single case reported by Bradfield and Perez [3]).

\section{Conclusion}

Glioblastoma in the pineal region is a very rare disease. However, in middle aged patients, a heterogeneously ringenhanced mass in the pineal region with leptomeningeal dissemination on MR imaging can raise the suspicion of glioblastoma. Even though it is impossible to conclude the best treatment modality, early adjuvant radiation therapy and chemotherapy after surgical resection appear to prolong the survival of patients with a pineal glioblastoma.

\section{Competing interests}

The authors declare that they have no competing interests.

\section{Authors' contributions}

KSM carried out the review of the literature and write up of the manuscript. SJ performed the surgery and was the coordinator of the study. JTY summarized the patient notes and carried out the literature search. KIY participated in the draft of the study, and in the conception of the study. MCL participated in the histopathological analysis, and in the coordination of the study. KHL participated in the draft of the study, and contributed to the work on the histopathology of the case including immunohistochemical work-up. All authors read and approved the final manuscript.

\section{Consent}

Written informed consent was obtained from the patient's relative for publication of this case report and any accompanying images. A copy of the written consent is available for review by the Editor-in-Chief of this journal.

\section{References}

I. Hirato J, Nakazato Y: Pathology of pineal region tumors. J Neuro-Oncol 200I, 54:239-249.

2. Amini A, Schmidt RH, Salzman KL, Chin SS, Couldwell WT: Glioblastoma multiforme of the pineal region. J Neuro-Oncol 2006, 79:307-3I4.

3. Bradfield JS, Perez CA: Pineal tumors and ectopic pinealomas. Analysis of treatment and failures. Radiology 1972, 103:399-406.

4. Cho BK, Wang KC, Nam DH, Kim DG, Jung HW, Kim HJ, Han DH, Choi KS: Pineal tumors: experience with 48 cases over 10 years. Childs Nerv Syst 1998, I 4:53-58.

5. DeGirolami U, Schmidek H: Clinicopathological study of $\mathbf{5 3}$ tumors of the pineal region. J Neurosurg 1973, 39:455-462.

6. Edwards MS, Hudgins RJ, Wilson CB, Levin VA, Wara WM: Pineal region tumors in children. J Neurosurg 1988, 68:689-697.
7. Frank F, Gaist G, Piazza G, Ricci RF, Sturiale C, Galassi E: Stereotaxic biopsy and radioactive implantation for interstitial therapy of tumors of the pineal region. Surg Neurol 1985, 23:275-280.

8. Gasparetto EL, Warszawiak D, Adam GP, Bleggi-Torres LF, de Carvalho Neto A: Glioblastoma multiforme of the pineal region: case report. Arq Neuropsiquiatr 2003, 6 I:468-472.

9. Kalyanaraman UP: Primary glioblastoma of the pineal gland. Arch Neurol 1979, 36:717-718.

10. Norbut AM, Mendelow H: Primary glioblastoma multiforme of the pineal region with leptomeningeal metastases: a case report. Cancer 1981, 47:592-596.

II. Pople IK, Arango JC, Scaravilli F: Intrinsic malignant glioma of the pineal gland. Childs Nerv Syst 1993, 9:422-424.

12. Toyooka T, Miyazawa T, Fukui S, Otani N, Nawashiro H, Shima K: Central neurogenic hyperventilation in a conscious man with CSF dissemination from a pineal glioblastoma. J Clin Neurosci 2005, I 2:834-837.

13. Vaquero J, Ramiro J, Martinez R: Glioblastoma multiforme of the pineal region. J Neurosurg Sci 1990, 34:|49-I50.

14. Kleihues P, Burger PC, Aldape KD, Brat DJ, Biernat W, Bigner DD: Glioblastoma. In WHO Classification of Tumours of the Central Nervous Systems 4th edition. Edited by: Louis DN, Ohgaki H, Wiestler OD, Cavenee WK. Lyon: IARC; 2007:33-49. [Bosman FT, Jaffe ES, Lakhani SR, Ohgaki H (Series Editors).]
Publish with Biomed Central and every scientist can read your work free of charge

"BioMed Central will be the most significant development for disseminating the results of biomedical research in our lifetime. "

Sir Paul Nurse, Cancer Research UK

Your research papers will be:

- available free of charge to the entire biomedical community

- peer reviewed and published immediately upon acceptance

- cited in PubMed and archived on PubMed Central

- yours - you keep the copyright

Submit your manuscript here:

http://www.biomedcentral.com/info/publishing_adv.asp
BioMedcentral 